\title{
Errata for Chemical and Pharmaceutical Bulletin
}

\begin{tabular}{c|c|c|l|l}
\hline \hline Vol. & Page & Line & \multicolumn{1}{c}{ Error } & \multicolumn{1}{c}{ Correction } \\
\hline 66 & 757 & Title & $\begin{array}{l}\text { Alkylated Benzoquinones: Ardisiaquinones A-H from the } \\
\text { Leaves of Ardisia quinquegona and Their Anti-Leishmania } \\
\text { Activity }\end{array}$ & $\begin{array}{l}\text { Alkylated Benzoquinones: Quinquequinones A-H from the } \\
\text { Activity }\end{array}$ \\
$757-762$ & $\begin{array}{l}\text { Trivial } \\
\text { names }\end{array}$ & $\underline{\text { ardisiaquinone(s) }}$ & quinquequinone(s) \\
\hline
\end{tabular}

